\title{
EU programme should increase support for social sciences'
}

[LISBON] The social sciences should play a more prominent role in plans for the European Union's fifth Framework programme for research (FP5), due to start in 1999, according to the research ministers of a number of member states.

Meeting in Lisbon, Portugal, on 4-6 April, ministers from Denmark, the Netherlands, Sweden, Portugal and Italy - as well as nonEU member Norway - gave their broad agreement to the idea that more needs to be and could be done to promote the social sciences at European level.

They suggested that the social sciences would benefit from more support from Brussels for the type of strategies that have been applied successfully to the natural sciences such as the creation of centres of excellence, the expansion of Europe-wide databases, and enhanced networking.

But some ministers, such as Jo Ritzen, the minister of education, science and culture in the Netherlands, went further to suggest that the growing economic and political integration of Europe is creating a new form of society, which the social sciences should take as an increasing focus of their research.

The meeting was organized by José Mariano Gago, Portugal's minister of science and technology, who said that it had arisen from a growing feeling that the social sciences need a higher profile in European science policy. "The political construction of Europe is an enormous challenge for the social sciences, just as it has been to natural scientists," said
Gago, who was formerly a physicist at the European Laboratory for Particle Physics (CERN) in Geneva, Switzerland.

Edith Cresson, European commissioner for research, said that current draft proposals for the four-year FP5 programme, which were due to be presented to the full commission this week (see box), already contain a strong commitment to support research in the social and economic sciences. The proposals aim in particular at helping to meet identified social goals, such as future transport systems.

"The social sciences have to give us a better capability to handle the consequences of the introduction and dissemination of new technologies, and they can also guide our research in the innovation field and improve our ability to target specific social needs," said Cresson.

Ironically, it is precisely such efforts to introduce a social agenda into technical research programmes that have upset some of the larger - and politically more conservative - EU member states. Their governments have been demanding a narrower focus to the Brussels research agenda, and were notable by their absence from the meeting in Lisbon.

But several participants argued that it was Europe's weakness in fields such as management science - as much as in the natural sciences - that is responsible for the relative weakness of its industrial economy compared to that of the United States.

A background paper produced by Italy's research ministry, for example, argued that

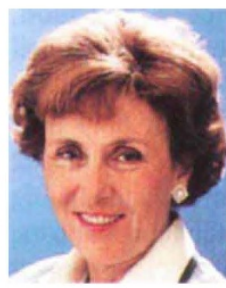

Cresson: planning for 'social agenda'. but how, enhanced support should be established for the social sciences at European level. Carl Tham, Sweden's minister for education and science, argued that, beyond supporting socio-economic research ties to specific objectives, FP5 should include a specific programme or 'key action' on the social sciences and humanities.

Guido Martinotti, former chair of the social science committee of the European Science Foundation, urged that a broader range of social sciences should be brought to bear on priorities that have already been identified, such as 'the city of tomorrow'. This view reflected complaints of an excessive emphasis on the technical dimension of such issues.

Politically, the impact of these discussions on the detailed contents of FP5 could depend to some extent on whether the Labour Party wins the British general election - and, if so, how far it is prepared to support the predominantly social democrat governments now seeking greater financial backing for the social sciences from Brussels.

DavidDickson

\section{Fellowships seem likely to win out over basic research in Europe}

\section{[MUNICH] The European Union's fifth}

Framework research programme (PP5) looks set to give much more support to research fellowships, but non-targeted basic research projects will not be a priority.

The European Commission's formal proposal for the five-year programme is expected to be made public this week. It will then need to win the approval of member states and the European parliament.

The proposal asks for the total budget of $P 5$ to be kept at least the same level, relative to member states' gross national product, as the ECU13.2 billion (US $\$ 15.2$ billion) of the fourth Framework programme (PP4). But it does not put an exact price on $\mathrm{P} 5$, since the commission's overall budget for its running period - 1999 to 2003 - has not yet been agreed. It is likely to be between EQU15 billion and ECU17 billion, according to observers.

The proposal holds few surprises for those who have seen early drafts, which were widely circulated outside the commission as part of its new policy of consulting a range of interested parties (see Nature 386, 5; 1997). It suggests three thematic programmes covering life sciences and the environment, information sciences, and industrial technologies. Each is earmarked for 28 per cent of the total funds.
Each thematic programme is divided into a series of strategic key actions plus an element dedicated to non-targeted generic technologies and support for infrastructure. The element for non-targeted basic research has disappeared. This was highlighted in earlier drafts, but was criticized by several member states, including Germany and Britain (see Nature 386, 205; 1997). Opponents had argued that basic research should be carried out only in the areas defined in the key actions.

The three additional, so-called 'horizontal', programmes receive different funding from that of comparable programmes in $\mathrm{P4} 4$. The budget share going to international cooperation falls from 5 per cent to 3.5 per cent, while that going to dissemination of research results remains at 2.5 per cent.

But the third horizontal action - training and mobility of researchers - is to increase its share from 6.5 to 10 per cent. It had become clear to the commission in the discussions with member states that this programme, which supports young European researchers working in a second EU country, was universally popular.

Euratom, Europe's atomic energy community, sees its share of the Framework 'cake' drop from 10 to 9 per cent. Alison Abbott 